\title{
INFLUENCES OF KNOWLEDGE ON BEHAVIOR IN AUTOMOBILES
}

\author{
S. David Leonard \\ Department of Psychology \\ University of Georgia \\ Athens, Georgia 30602, USA \\ E-mail: dleonard@egon.psy.uga.edu
}

\begin{abstract}
Summary: Behaviors are generally a function of desired effects and knowledge about means of producing those effects. In using automobiles for the general activity of transportation, individuals may also have an implicit concern with maintaining their safety and their passengers' safety. This study involved self-reported practices and knowledge of procedures important for maximizing safe use of automobiles. Subjects described their behaviors and evaluated some warnings used to provide safety information. They were also asked to indicate how relevant they thought the information in the warnings would be for them. Responses indicated support for previous findings that warnings employing standard procedures were more likely to be effective but also suggested many individuals were unaware of some existing warnings, as well as other sorts of safety information. Results are discussed in terms of the need for improving safety information, including warnings.
\end{abstract}

\section{INTRODUCTION}

Warnings provide important sources of information in a variety of situations. Use of warnings in automobiles is no exception. The question of what warnings to provide and how to present them is not always easy to answer. Previous research (Laughery et al., 2002) has shown that using warnings designed on principles accepted in the human factors/ergonomics approach to warnings is thought to increase the likelihood that they will be noticed and obeyed. Further, evidence has been shown to support the notion that more information about hazards increases the subjective concern for avoiding the hazards (Leonard, 2002). In addition, sources of information about safe practices in driving are not widely used by most drivers. Studies by Leonard (2001) and Mehlbacher, Wogalter, and Laughery (2001) have shown limited use, at best, of owners' manuals for automobiles. In effect, as is the case with manuals for other products, these manuals are used almost exclusively as reference works.

The study reported here was designed to obtain information about how some hazards of driving may be approached by the general public as exemplified by young adults in particular. In addition, a partial replication of the Laughery et al. (2002) procedure was performed to see if there was a relationship between information provided in warnings and the concern of respondents for having that knowledge. Thus, in addition to evaluating warnings for their likelihood of being noticed, read, understood, and complied with, respondents were asked to indicate whether they had previously encountered the warnings presented and whether or not they might previously have been more concerned about the situations had they known the information in the warnings. It was presumed that those individuals who had previously seen the warnings would recall that fact. 


\section{Methods}

Undergraduate volunteers from psychology classes participated to fulfill course requirements. A total of 160 respondents provided usable responses. There were 90 females and 70 males. The procedure involved completing a survey that collected information about their driving and riding habits, what type of vehicle they drove, and what they knew about certain safety questions. Among other items, the questions in the survey touched on the use of seat belts, lap belts with automatic shoulder belts, head restraints, and reclining in vehicles. After completing the survey, the participants were asked to compare certain formats of warnings in terms of how likely they were to be noticed, read, understood, and complied with. The warnings were associated with underinflation of tires, reclining the seat back while the automobile is in motion, the rollover tendencies of SUVs, and lying down in the rear seat. A few respondents also received warnings about the need to use the lap belt with an automatic shoulder belt. Not all warnings were rated by all participants.

After evaluating the warning forms, respondents were asked whether some of the hazards covered might have been of concern to them previously if they had known of the hazards presented in the session. The specific items covered were the tendency of SUVs to roll over, the reclining of the front seat, and the use of lap belts with automatic shoulder belts.

\section{Results}

The survey asked about the behaviors of the respondents with respect to reclining the front seat and lying down in the rear seat. Most (84\%) indicated they had reclined in the front seat and had lain down in the rear seat (89\%), although typically they indicated the behaviors were not frequent. In most cases, the individuals said they only did so when they were tired or on a long trip. Further, only 28 percent of respondents said they made a practice of frequent adjustment of the head restraints.

Table 1. Mean Percentages Judged Likely to Act as Listed to Warning as a Function of Format

\begin{tabular}{|c|c|c|c|c|c|c|c|c|c|}
\hline \multirow[b]{2}{*}{ Hazard } & \multirow[b]{2}{*}{$\underline{\mathrm{N}}$} & \multicolumn{2}{|c|}{$\begin{array}{c}\text { Notice } \\
\text { warning }\end{array}$} & \multicolumn{2}{|c|}{$\begin{array}{c}\text { Read } \\
\text { warning }\end{array}$} & \multicolumn{2}{|c|}{$\begin{array}{l}\text { Understand } \\
\text { warning }\end{array}$} & \multicolumn{2}{|c|}{$\begin{array}{l}\text { Comply with } \\
\text { warning }\end{array}$} \\
\hline & & ANSI & non & ANSI & non & ANSI & non & ANSI & non \\
\hline Reclined seat & 81 & 81.7 & 35.1 & 69.7 & 23.1 & 69.3 & 39.8 & 40.6 & 20.0 \\
\hline Lying in rear seat & 64 & 83.9 & 36.7 & 71.6 & 24.8 & 77.1 & 50.3 & 51.5 & 31.9 \\
\hline SUV rollovers & 93 & 83.8 & 54.3 & 72.4 & 38.7 & 70.2 & 53.1 & 64.9 & 41.1 \\
\hline Tire underinflation & 160 & 64.9 & 48.1 & 50.4 & 36.7 & 53.9 & 39.8 & 41.7 & 30.4 \\
\hline
\end{tabular}

Laughery, Paige, Laughery, Wogalter, Kalsher, and Leonard (2002), using respondents from five different states, found that warnings designed to conform to the ANSI Z535.4 standard (1998) were rated about 1.5 to 2 times as effective as warnings that did not follow that format. As seen in Table 1, similar results were obtained from these participants. Little practical difference was found between the sexes, thus the data show the combined results. Note in Table 1 that not all respondents received each pair of warnings. The warning evaluation procedure produced some 
evidence for the possible effects of warnings in that many respondents indicated that had they known the information in the warnings, they would have had greater concern for such problems as reclining the passenger seat back (54\%), and the propensity for SUVs to roll over (59\%).

Further evidence for the importance of good warnings comes from an evaluation of the responses of individuals who drove SUVs. Of those who drove vehicles from the 1999 model year and later, 53\% listed the possibility of rollovers in response to a question about which of the warnings they had previously experienced, while only $30 \%$ of those who drove earlier models did so. Because of the small numbers of these drivers, that result was only marginally dependable, $\chi_{1}^{2}=3.79, .10>p>.05$.

Another interesting phenomenon found in the survey results was the reported use of seat belts. Respondents were asked to indicate how often they wore their seat belts while on the highway and on surface streets. For highway driving, 94 percent said they always wore their seat belts, while for driving on surface streets, only 80 percent said they always wore them. This result was statistically dependable, $\chi_{1}^{2}=8.12, p<.05$. This is in accord with an informal survey that showed only about 60-65 percent of drivers on city streets wore their seat belts, while about 90 percent wore them on the freeways.

The information about most of the hazards is limited because relatively few individuals seek out information about safety. As noted by Leonard (2001), owners' manuals are seldom consulted for anything involving safety. In this survey 66 percent of those responding to what topics they examined indicated they read the manual to get information about the radio, and only 30 percent of them said they read the manual for safety tips. The only category checked less frequently as a topic examined in the manual was the information about tire pressure. Of course, tire pressure is a significant safety factor.

\section{CONCLUSIONS}

The fact that knowledge about significant safety problems is limited comes as no surprise. A number of previous studies have found similar results (e.g., Leonard \& Karnes, 1998; Laughery, Laughery \& Lovvoll, 1994). Further, the results concerning use of owners' manuals merely reinforce the findings in the previous studies by Mehlenbacher et al. (2002) and Leonard (2001). However, the question of how to provide appropriate information is still an open one. The fact that individuals who had evaluated the warnings indicated the information contained in those warnings would have produced greater concern in them had they known it earlier indicates that warnings are a useful source of information. In addition, the effectiveness of warnings as far as presenting information is supported by the fact that there was a greater tendency (though of low statistical dependability) to recall having seen such warnings among individuals who drove SUVs manufactured after more stringent warnings were required to be on the vehicles.

Unfortunately, the survey results indicate unsafe behaviors exist in a large proportion of the driving public. Inasmuch as there is probably some tendency to play down one's inadequacies, it is likely that those unsafe behaviors occur somewhat more frequently than described. The use of appropriate warnings may ameliorate the situation, but the number of different hazards makes it difficult to include all the items in permanent signs on the typical automobile. One suggestion presented by Leonard (2001) was to have a separate manual for safety information. Inasmuch as 
some automakers now have separate manuals for various functions, e.g., the sound system, this might be useful. However, the percentage of individuals reading such a manual still might not reach the level desired. Many people think they have adequate knowledge already. However, a high percentage of individuals consider their parents as the source of the most important safety information (cf. Leonard, 2001). Because many changes have affected safe driving behavior over time (e.g., automatic braking systems) your father's safe driving may no longer be appropriate. One solution that might be feasible soon, if not already, would be to incorporate safety questions in a test to be taken upon obtaining and renewing driving licenses. With the capability of presenting the test to large numbers of individuals by computer technology this would not require much additional time for the examiners and could produce considerable benefits. Indeed, such a test could be administered over the Internet, because the purpose is not to grade individuals but to get them to consider the safety information. If one considers only the costs of hospital care for persons injured because of failure to act appropriately, it might far outweigh the cost of administering the test.

More research should be done to devise appropriate warnings and their influence on behavior, but these results show that some benefits can come from warnings.

\section{REFERENCES}

Laughery, K.R., Laughery, K.A. \& Lovvol, D.R. (1996). Automatic shoulder belt manual lap belt restraint systems: Human factors analyses of case studies data. Proceedings of the Human Factors Society 40th Annual Meeting-1996. Santa Monica, CA: Human Factors Society, 492-496.

Laughery, K.R., Sr., Paige, D.L., Laughery, B.R., Wogalter M.S., Kalsher, M.J. \& Leonard, S.D. (2002). Guidelines for warnings design: Do they matter? Proceedings of the Human Factors Society 46th Annual Meeting-2002. Santa Monica, CA: Human Factors Society, 1708-1712.

Leonard, S.D. (2001). Relation of Owner's Manual to Safety. Proceedings of the First International Driving Symposium on Human Factors in Driver Assessment, Training and Vehicle Design. Iowa City, IA: University of Iowa Public Policy Center, 125-130.

Leonard, S.D. (2002). Effects of information on subjective expectations of behavior. Proceedings of The XVI Annual International Ergonomics and Safety Conference 2002, International Society for Occupational Ergonomics and Safety.

Leonard, S.D. \& Karnes, E.W. (1998). Perception of risk in automobiles: is it accurate? Proceedings of the Human Factors Society 42nd Annual Meeting-1998. Santa Monica, CA: Human Factors Society, 1083-1087.

Mehlenbacher, B., Wogalter, M. S. \& Laughery, K.R. (2002). On the reading of product owner's manuals: Perception and product complexity. Proceedings of the Human Factors Society 45th Annual Meeting - 2001. Santa Monica, CA: Human Factors Society, 730-734. 